\title{
Conceptualising the Circular Economy Potential of Construction and Demolition Waste: An Integrative Literature Review
}

\author{
Vasilios Papastamoulis ${ }^{1, *(\mathbb{D})}$, Kerry London ${ }^{2}$, Yingbin Feng ${ }^{1} \mathbb{D}$, Peng Zhang ${ }^{1}$, Robert Crocker ${ }^{3} \mathbb{D}$ \\ and Petros Patias 4 (D)
}

\section{check for}

updates

Citation: Papastamoulis, V.; London, K.; Feng, Y.; Zhang, P.; Crocker, R.;

Patias, P. Conceptualising the Circular Economy Potential of Construction and Demolition Waste: An Integrative Literature Review. Recycling 2021, 6, 61. https://doi.org/10.3390/ recycling6030061

Academic Editors: Abdol R. Chini, Salman Shooshtarian and Tayyab Maqsood

Received: 30 July 2021

Accepted: 10 September 2021

Published: 15 September 2021

Publisher's Note: MDPI stays neutral with regard to jurisdictional claims in published maps and institutional affiliations.

Copyright: (c) 2021 by the authors. Licensee MDPI, Basel, Switzerland. This article is an open access article distributed under the terms and conditions of the Creative Commons Attribution (CC BY) license (https:// creativecommons.org/licenses/by/ $4.0 /)$
1 School of Engineering, Design \& Built Environment, Western Sydney University, Penrith, NSW 2751, Australia; Y.Feng@westernsydney.edu.au (Y.F.); P.Zhang@westernsydney.edu.au (P.Z.)

2 Office of the Pro Vice Chancellor Research, Torrens University Australia, Sydney, NSW 2000, Australia; kerry.london@laureate.edu.au

3 School of Architecture, Art and Design, University of South Australia, Adelaide, SA 5001, Australia; Robert.Crocker@unisa.edu.au

4 School of Rural \& Surveying Engineering, Aristotle University of Thessaloniki, 54124 Thessaloniki, Greece; patias@auth.gr

* Correspondence: V.Papastamoulis@westernsydney.edu.au
Abstract: Traditionally, construction and demolition waste (CDW) materials have been considered to be unwanted, surplus, or wastage materials or materials with zero value. Such a conceptualisation only embraces a negative aspect, which underpins the disposal of reusable and recyclable CDW materials in landfills, thus damaging the circular economy and the environment. The scope of this research was to conceptualise the circular economy potential of non-hazardous construction and demolition waste, which can be used as a resource for advancing the circular economy and sustainability in the built environment. Thus, the abbreviation 'CEPCDR' is used for this purpose. The study employs an integrative literature review to understand in depth whether the rationale in the existing CDW definitions advocates for the circular economy. Instead, the literature showed that the current definitions mainly support quantitative, economic, or classification needs, respectively. That is because they lack consideration of the dynamic nature of CDW materials, which embraces the spatial and temporal dimensions. The former involves the geographic context in which the CDW phenomenon eventuates, while the latter concerns the lifecycle of materials. This study contributes to the body of knowledge by conceptualising the CEPCDR using a holistic approach that includes five dimensions: the social, economic, environmental, spatial, and temporal perspectives. Furthermore, the study seeks to drive future research in measuring the CEPCDR.

Keywords: construction and demolition waste; definition; legislation; circular economy; lifecycle

\section{Introduction}

Globally, billions of tons of construction and demolition waste (CDW) materials are disposed of annually in landfills, causing severe social, economic, and environmental harm [1-3]. In China, around 2.36 billion tons of CDW were generated in 2018 [4], while only $5-10 \%$ of this quantity was recycled [5]. In the same year, the European Union (excluding the United Kingdom) produced 835 million tons, where the landfilling rates in Cyprus, France, Slovakia, and Sweden were 43\%, 29\%, 47\%, and 39\%, respectively [6,7]. In the United States, more than 600 million tons of CDW materials were produced in 2018, of which approximately $30 \%$ ended up in landfills [8]. The landfilling rates are also significantly high in smaller CDW-generating countries, such as India, Brazil, and Australia, at $70-90 \%, 92 \%$, and $27 \%$, respectively [9-11].

Considering that up to $95 \%$ of non-hazardous CDW materials are reusable and recyclable [12-14], the loss for the circular economy is tremendously high. Despite the magni- 
tude of the problem, CDW materials are not effectively managed around the world [15-18]. Inconsistencies in definitions and classifications of the CDW stream contribute to this problem $[19,20]$. Specifically, a plethora of different terms, such as "by-product", "surplus", "excess", "wastage", "difference", "substance", "unwanted material", "loss", and "inefficiency", have been used to describe CDW materials over the years [21-25]. The variation in definitions may lead to vague classifications for the same types of CDW materials, eventually inducing disparities in waste analytics $[2,19,26-28]$. This problem is of great importance as recyclable CDW materials may improperly end up in landfills, damaging the environment, thus supporting the linear economy [20].

The need for a transition from the obsolete linear economic model of "make-usedispose" to an inclusive circular economy is an emerging theme for the construction industry [29-31]. The philosophy of the circular economy is based on the "3Re" policy, which stands for the terms 'reuse', 'recycling', and 'recovery' [32,33]. Thus, the circular

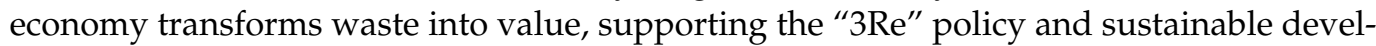
opment $[4,29,33,34]$. CDW materials can be a key driver of this transformation as most of them can be reused or recycled [8]. Therefore, to advance the circular economy, we need to effectively manage the recycling potential of CDW materials. In other words, we need to accurately define and measure the material potential that results in construction sites and is suitable for reuse, recycling, or recovery.

Recent studies have been conducted regarding the recycling potential of CDW materials. Ginga, Ongpeng, Daly, and Klarissa [4] proposed a framework to overcome the obstacles to promoting the reuse of CDW materials in new construction applications in China. Their framework involves the treatment scenarios of CDW materials (reuse and recycling on-site and off-site, recovery, and landfilling) as well as their transportation and storage phases. Similarly, Ruiz, Ramón, and Domingo [18] developed a theoretical framework in Spain that involves 14 strategies and considers five lifecycle stages of CDW materials to maximise their applications in the industry as secondary materials [18] (p. 11).

Tazi, et al. [35] assessed the circularity of inert building materials for the French dwelling sector by employing Material Flow Analysis (MFA) at a regional level. Their model considers several variables related to location, number of dwellings, total floor area, and end-of-life scenario as well as market variables. Lederer, et al. [36] carried out a case study in Vienna, in Austria, to measure the recycling potential of mineral CDW materials specifically. Their model also embraced the MFA to estimate the flows of four inert building materials: concrete, asphalt, bricks, and gravel.

Although these notable studies have developed frameworks, models, and methodologies to measure the recycling potential of CDW materials accurately, they fail to provide a unique definition for the potential of the circular economy. Specifically, Tazi, Idir, and Ben Fraj [35] defined the recyclability rate of a region as the ratio of the average flows of inert materials (e.g., concrete, bricks, stones, asphalt, and tiles, including mortar) that can be recycled in a year to the average amount of CDW materials generated in a region in the same year [35] (p. 11). In a similar fashion, Lederer, Gassner, Kleemann, and Fellner [36] measured it as the ratio of material mass balance in tonnes produced in a year; the material mass is estimated with the MFA formula as the difference between the output material flow and the stored material. However, they did not state any specific definition for the circular economy potential.

Definitions play a critical role in CDW management, particularly in reporting and recording the resulting recycling potential [37] (p. 317). Therefore, the conceptualisation of the circular economy potential for CDW materials may foster their diversion from landfills, advancing the circular economy. The transformation should involve a multidimensional conceptual approach for the circular economy potential, because the CDW phenomenon has a dynamic nature. Particularly, the resulting materials need to be allocated for treatment or storage across different geographic locations (e.g., construction sites, material banks, resource centres, and landfills) throughout their lifespan. 
The spatial dimension was included in the conceptual definition of the term 'waste'; the term originates from the old French word "vastum", which was introduced in the Middle Ages to describe "an empty space or a desolate region" [38] (p. 200). Furthermore, the temporal dimension involves the lifecycle impact of CDW materials. Specifically, it includes the carbon dioxide emissions, which are associated with the transportation and treatment phase of CDW materials [6]. Both phases are related to the circular economy. Apart from that, the social value of CDW materials should be considered in the conceptualisation of the circular economy potential. The latter is inherently related to the development of resilient local communities through the growth of the circular economy.

As a result, the circular economy potential of CDW materials is a multidimensional concept; therefore, it should be conceptualised from a holistic perspective. This is further underpinned by the holistic concept of the circular economy. For instance, Nobre and Tavares [34] defined the circular economy by considering the minimisation of waste and the lifecycle impact of materials as well as the end users and the impacted ecosystems. Consequently, the circular economy potential may integrate five dimensions: social, economic, environmental, spatial, and temporal.

This study aims to conceptualise the circular economy potential of non-hazardous CDW materials to address the gap in the literature with the aim of advancing the circular economy and sustainability in the built environment. For this purpose, an integrative literature review was conducted to understand the rationale in the existing CDW definitions in depth and critically discuss their conceptual approach. Furthermore, the current work seeks to raise awareness about the value of CDW materials for the circular economy with the aim of transforming the industry's mindset as well as driving future research in the domain of CDW definitions.

The research showed that the current CDW definitions fail to embrace the five dimensions mentioned above, as their scope is mainly limited to quantitative, economic, and classification purposes. In addition, the existing definitions fail to recognise the circular economy potential of CDW materials since they consider them as unwanted, wastage, or surplus materials with minimal value [22,39-41]. This kind of conceptual approach embraces only the negative aspect of the CDW materials, which underpins the linear economy rather than the circular economy and environmental sustainability in the construction industry.

In conclusion, the objectives of the present study are as follows:

- To identify gaps in the literature regarding CDW definitions; and

- To bridge these gaps by conceptualising the circular economy potential of the nonhazardous CDW materials.

\section{Methodology}

An integrative literature review was adopted to accomplish the research objectives. This method enables a deeper understanding of the research topic by reviewing both the scholarly and grey literature [42]. Some of the largest and most credible online scientific databases, including Google Scholar, ScienceDirect, Scopus, and Web of Science (WoS), were targeted to retrieve the relevant material [43].

The systematic search of the scholarly literature was initially held by using the keywords "waste" and "definition" in the fields "article title" and "article title/abstract/keywords", respectively. Furthermore, the Boolean operator "AND" was utilised. The word "waste" was used as CDW materials are a major component of the entire waste stream and the research aims indirectly involve the different aspects of the conceptual waste definitions. Additionally, there was no limitation regarding the year of the targeted published sources to understand the rationale behind the waste definitions in depth. 
The first run was held in Scopus and WoS, which resulted in 1065 and 681 sources, respectively. After searching for duplicates, 686 references were removed. The second run was carried out in EndNote management software by using the keywords "construction" and "demolition" in the field "title" of the search panel of the software. The Boolean operators "AND" and "OR" were employed to guide the search. Eventually, 34 peerreviewed sources were retained after their titles and abstracts were manually reviewed. The third and final run was completed in Google Scholar and ScienceDirect. The same keywords were used, and another 33 scholarly sources were located, of which 4 were irrelevant to this research. Therefore, 67 peer-reviewed sources were finally obtained.

Regarding the grey literature, the data were retrieved from several governmental and organisational websites as well as industry reports through the Google search engine. For this purpose, the keywords "legislation" and "classification" were further used, and, initially, 35 sources were located. However, 6 of them were not related to the scope of this research, and thus 29 non-scholarly sources related to legislative definitions were finally considered.

In summary, 96 sources in total were included in this study, of which $39 \%$ originated from the EU-28, 25\% from Asia, 21\% from the United States, and 15\% from Australia. It is worth mentioning that the geographic domain of the grey literature focuses on Australia, China, Europe, India, and the United States, as these countries/continents constitute some of the major waste generators per capita in the world $[2,25,44]$. The scientific domain of the literature consists of $64 \%$ journal papers, $17 \%$ industry reports, $8 \%$ books /book chapters, $9 \%$ conference papers, and $2 \%$ governmental websites. Figure 1 illustrates the flow chart of this study. 


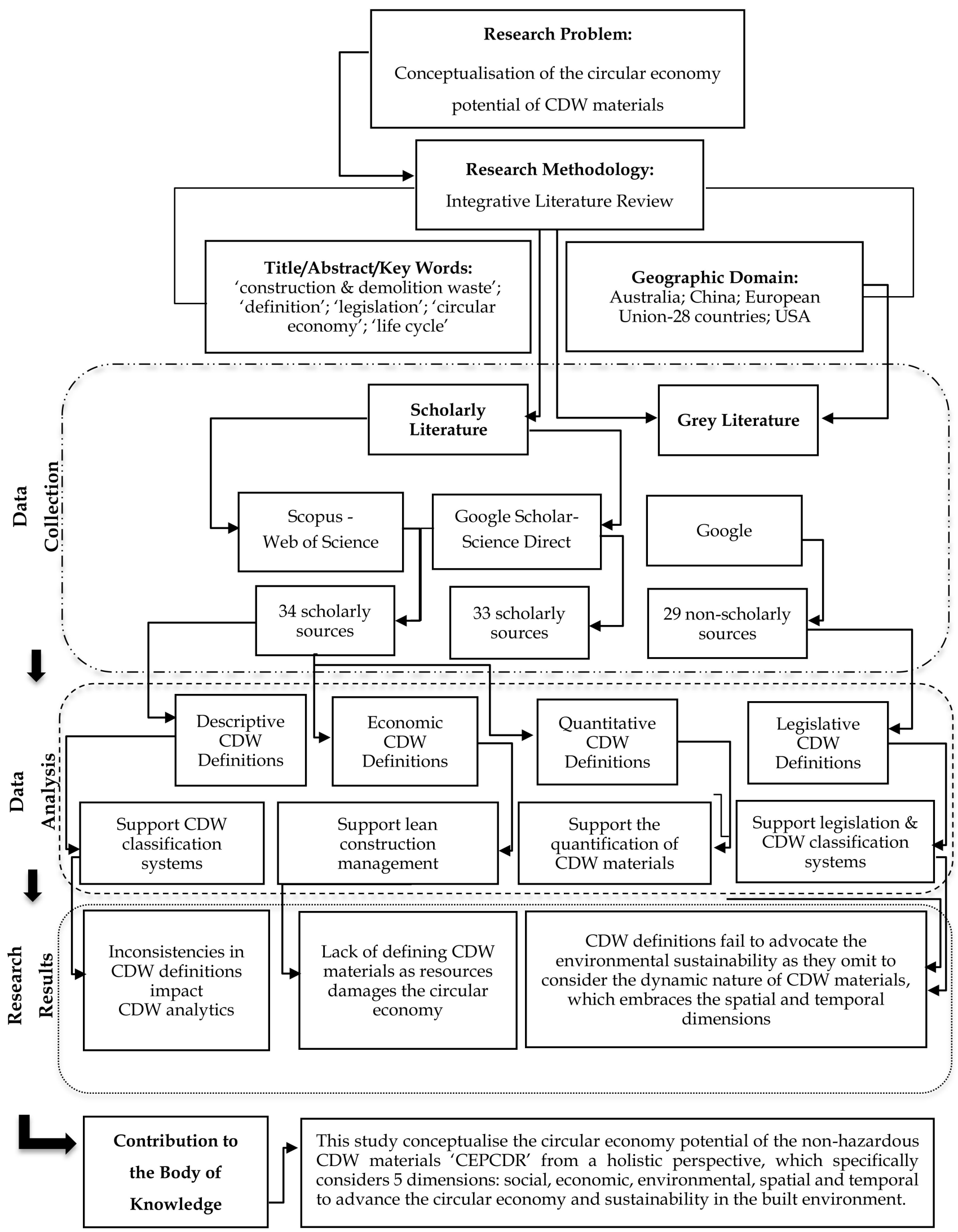

Figure 1. Research flow diagram. 


\section{Results}

\subsection{Scholarly Definitions of CDW Materials}

The scholarly literature showed that the definitions regarding CDW materials can be grouped based on their terminology and scope into three main categories: (1) quantitative definitions, (2) descriptive definitions, and (3) economic definitions. Table 1 depicts the scholarly definitions in these categories. The first category involves definitions that have been developed to support the estimation of the generated quantities of CDW materials. The second category usually encompasses descriptive definitions that describe and classify CDW materials, while the third category includes definitions that embrace monetary terminology to support lean construction management.

Table 1. Descriptive, economic, and quantitative CDW definitions.

\begin{tabular}{|c|c|c|}
\hline Author \& Year & $\begin{array}{l}\text { CDW } \\
\text { Definition }\end{array}$ & $\begin{array}{l}\text { CDW } \\
\text { Category }\end{array}$ \\
\hline $\begin{array}{l}\text { Skoyles and Hussey } \\
1974\end{array}$ & $\begin{array}{l}\text { "The surplus between materials ordered, delivered, and accepted and those used } \\
\text { properly for the execution of the building project" }\end{array}$ & Quantitative \\
\hline $\begin{array}{l}\text { Skoyles } \\
1976\end{array}$ & "Direct waste" refers to material wastage, while "indirect waste" to monetary loss & $\begin{array}{l}\text { Quantitative and } \\
\text { Economic }\end{array}$ \\
\hline $\begin{array}{l}\text { Skoyles, E. and Skoyles, J. } \\
1987\end{array}$ & $\begin{array}{l}\text { "A material which needed to be transported elsewhere from a construction site or used } \\
\text { on the site itself other than the intended purpose of the project due to damage, excess, or } \\
\text { non-use or which cannot be used due to non-compliance with the project's specifications, } \\
\text { or which is a 'by-product' of the construction process" }\end{array}$ & $\begin{array}{l}\text { Quantitative and } \\
\text { Economic }\end{array}$ \\
\hline $\begin{array}{l}\text { Agenda } 21(\mathrm{UN}) \\
1992\end{array}$ & $\begin{array}{l}\text { "The material wastage can be defined as the amount consumed in addition to the } \\
\text { planned material" }\end{array}$ & Quantitative \\
\hline $\begin{array}{l}\text { Koskela } \\
1992\end{array}$ & $\begin{array}{l}\text { "Any inefficiency that results in the use of equipment, materials, labour, or capital in } \\
\text { larger quantities than those considered as necessary in the production of a building. } \\
\text { Also, any activity that takes time, resources, or space but does not add value" }\end{array}$ & Economic \\
\hline $\begin{array}{l}\text { HK Polytechnic School } \\
1993\end{array}$ & $\begin{array}{l}\text { "The amount of by-product removed from construction sites for a recycling, reusing, or } \\
\text { disposing of purpose" }\end{array}$ & $\begin{array}{l}\text { Quantitative and } \\
\text { Economic }\end{array}$ \\
\hline $\begin{array}{l}\text { Tchobanoglous et al., } \\
1993\end{array}$ & $\begin{array}{l}\text { "The relatively clean, heterogeneous building materials generated from the various } \\
\text { construction activities" }\end{array}$ & Descriptive \\
\hline $\begin{array}{l}\text { Alarcon } \\
1997\end{array}$ & $\begin{array}{l}\text { "Anything different from the absolute minimum number of resources of materials, } \\
\text { equipment, and manpower necessary to add value to the product" }\end{array}$ & Economic \\
\hline $\begin{array}{l}\text { Formoso et al., } \\
1999\end{array}$ & $\begin{array}{l}\text { "Any losses produced by activities that generate direct or indirect costs, but do not add } \\
\text { value to the product from the point of view of the client" }\end{array}$ & Economic \\
\hline $\begin{array}{l}\text { Ekanayaka and Ofori } \\
\qquad 2000\end{array}$ & $\begin{array}{l}\text { "Construction waste can be divided into three principal categories: material, labour, and } \\
\text { machinery waste, and they derive from non-renewable resources" }\end{array}$ & Economic \\
\hline $\begin{array}{l}\text { Shen et al., } \\
2000\end{array}$ & $\begin{array}{l}\text { "The difference between the value of materials delivered and accepted on site and those } \\
\text { properly used as specified and accurately measured in the work, after deducting the cost } \\
\text { saving of substituted materials transferred elsewhere, in which unnecessary cost and } \\
\text { time may be incurred by materials wastage" }\end{array}$ & $\begin{array}{l}\text { Quantitative and } \\
\text { Economic }\end{array}$ \\
\hline $\begin{array}{l}\text { Formoso et al., } \\
2002\end{array}$ & $\begin{array}{l}\text { "The difference between the number of materials effectively purchased by the company } \\
\text { less the number of existing inventories in relation to the amount of materials defined by } \\
\text { the measurement of work done" }\end{array}$ & Quantitative \\
\hline $\begin{array}{l}\text { Shen et al., } \\
2004\end{array}$ & $\begin{array}{l}\text { "The form of building debris, rubble, earth, concrete, steel, timber, and mixed site } \\
\text { clearance materials, arising from various construction activities including land } \\
\text { excavation, site clearance, demolition activities, roadwork, and building renovation" }\end{array}$ & Descriptive \\
\hline $\begin{array}{l}\text { The UK WRAP } \\
2006\end{array}$ & $\begin{array}{l}\text { "The excess or damaged or temporarily used products during construction, renovation, } \\
\text { and demolition work" }\end{array}$ & Descriptive \\
\hline $\begin{array}{l}\text { Roche and Hegarty } \\
2006\end{array}$ & $\begin{array}{l}\text { "The surplus and damaged products and materials that arise from construction, } \\
\text { renovation, demolition, and other construction activities" }\end{array}$ & $\begin{array}{l}\text { Quantitative and } \\
\text { Descriptive }\end{array}$ \\
\hline $\begin{array}{l}\text { Poon } \\
2007\end{array}$ & $\begin{array}{l}\text { "As a mixture of inert and non-inert materials arising from construction, excavation, } \\
\text { renovation, demolition, roadwork, and other construction-related activities" }\end{array}$ & Descriptive \\
\hline $\begin{array}{l}\text { Tam et al., } \\
2007\end{array}$ & "Any unwanted product from the construction, renovation, and demolition activities" & Descriptive \\
\hline
\end{tabular}


Table 1. Cont.

\begin{tabular}{|c|c|c|}
\hline Author \& Year & $\begin{array}{l}\text { CDW } \\
\text { Definition }\end{array}$ & $\begin{array}{l}\text { CDW } \\
\text { Category }\end{array}$ \\
\hline $\begin{array}{l}\text { Kofoworola and Gheewala } \\
\qquad 2009\end{array}$ & "The solid waste that arises from construction, renovation, and demolition activities" & Descriptive \\
\hline $\begin{array}{l}\text { Lu and Yuan } \\
2011\end{array}$ & $\begin{array}{l}\text { "Any waste or damaged materials generated by site clearance, excavation, construction, } \\
\text { refurbishment, renovation, demolition, and road works" }\end{array}$ & Descriptive \\
\hline $\begin{array}{l}\text { Jain } \\
2012\end{array}$ & $\begin{array}{l}\text { "Activities such as construction, renovation, or demolition of structures generating an } \\
\text { inert and non-inert material defined as construction waste" }\end{array}$ & Descriptive \\
\hline $\begin{array}{l}\text { Nagapan et al., } \\
2012\end{array}$ & $\begin{array}{l}\text { "Physical waste; any material by-product of human and industrial activity that has no } \\
\text { residual value" }\end{array}$ & Economic \\
\hline $\begin{array}{l}\text { Rajendran } \\
2012\end{array}$ & $\begin{array}{l}\text { "Any waste related to design changes, unused material, packaging waste, and errors } \\
\text { in designs" }\end{array}$ & Economic \\
\hline $\begin{array}{l}\text { Muhwezi et al., } \\
2012\end{array}$ & $\begin{array}{l}\text { "Any material that needs to be recycled; reused other than for a particular purpose } \\
\text { because of damage, excess, non-use, or non-compliance with the specifications needed" }\end{array}$ & Economic \\
\hline $\begin{array}{l}\text { Denzer et al. } \\
\quad 2015\end{array}$ & $\begin{array}{l}\text { "CDW materials can be defined as (i) object waste (activities and outcomes), (ii) effort } \\
\text { waste (resource efficiency), and (iii) value waste (value loss for clients)" }\end{array}$ & Economic \\
\hline $\begin{array}{c}\text { Martos } \\
2018\end{array}$ & $\begin{array}{l}\text { "The waste generated by the economic activities involving the construction, } \\
\text { maintenance, demolition, and deconstruction of buildings and civil works" }\end{array}$ & $\begin{array}{l}\text { Descriptive and } \\
\text { Economic }\end{array}$ \\
\hline $\begin{array}{l}\text { Menegaki and Damigos } \\
2018\end{array}$ & $\begin{array}{l}\text { "The surplus between materials ordered, delivered, and accepted and those used } \\
\text { properly for the execution of the building project" }\end{array}$ & Quantitative \\
\hline $\begin{array}{c}\text { Wang et al., } \\
2019\end{array}$ & $\begin{array}{l}\text { "The waste material generated from the construction of residential buildings, } \\
\text { commercial buildings, public buildings, and industrial buildings, excluding } \\
\text { excavated soil" }\end{array}$ & Descriptive \\
\hline
\end{tabular}

Regarding the first category, most definitions use words such as "quantity", "amount", "percentage", "surplus", or "excess", indicating that the term "CDW" should basically concern something that is tangible and can be measured, such as material wastage. The quantitative definitions focus on the minimisation of the generation of building waste materials in construction projects. As can be seen from Table 1, Skoyles and Hussey [21] were amongst the pioneers who proposed a comprehensive quantitative definition regarding the resultant building waste materials in U.K. construction sites. They defined CDW as "the difference between the quantities of materials ordered and those that are used properly during the installation of a building project" [21].

Based on this concept, several other scholars and government bodies proposed similar definitions for CDW materials. The United Nations developed in 1992, in Rio, in Brazil, the "Agenda 21" to support sustainable development, in which CDW materials are defined as "material wastage that exceeds the scheduled quantity" [45,46]. Shen, et al. [47] additionally introduced the economic dimension into CDW definitions by considering their associated value and cost for the construction industry in Hong Kong [47]. Formoso, Soibelman, De Cesare, and Isatto [39] linked the storage quantities apart from the used material in Brazilian construction sites [39], while Roche and Hegarty [48] and Menegaki and Damigos [25] defined CDW as "the surplus between the material ordered and used in situ" in Ireland and Greece, respectively.

As can be seen from Table 1, quantitative definitions place emphasis on the material nature of the term "CDW", which can be mathematically measured either as a mass balance or as a volume. Furthermore, the dominance of the term "material" in quantitative definitions is evident through the frequent use of that word. Thereby, such definitions may enhance the production of robust CDW analytics regarding the recycling potential of CDW materials, underpinning the circular economy. Apart from that, they can help construction managers to control the material wastage in a tangible way, thus saving project costs, while the environment can be eventually protected. Consequently, CDW definitions may embrace both the economic and environmental dimensions.

The literature shows that quantitative and monetary terms have been used interchangeably. Table 1 lists such mixed CDW definitions [23,25,39,48,49]. However, most of 
these definitions employ terms with an identical or overlapping meaning, thus leading to a vague interpretation. For instance, the definition given by the Hong Kong Polytechnic University in 1993 embraces the terminology "amount of by-product", which presents generality as it does not clarify the type of the by-product. Additionally, the word "amount" may refer to the volume or mass of the generated CDW materials.

Similarly, the term "any losses" in the definition proposed by Formoso, Isatto, and Hirota [23] could refer to the resultant quantity of CDW materials or to the associated costs with the relevant construction activities. Even if the definitions imply that the words "amount" and "losses" may refer to the quantity of the generated CDW materials, they do not specify the units in which they should be measured. For example, these units could be in cubic meters or in kilograms for the resulting volume or mass of CDW materials, respectively.

Apart from the vague embracement of the economic and environmental dimensions, the literature discloses that CDW definitions may also integrate the spatial dimension in an unclear manner. For example, Skoyles and Skoyles [49] include in their definition the word "elsewhere", which does not determine a specific area in which the CDW materials should be transported. Perhaps a phrase such as "within the regional boundaries" or "to the nearest authorised treatment facility" could support the CE. As a result, CDW definitions may encompass the spatial dimension.

Regarding the "descriptive definitions", CDW materials are mainly defined based on their composition, the type of activities (construction, demolition, etc.), or the type of projects in which the materials are produced [25,47,50-53]. Such types of definitions have been widely adopted in most waste management strategies to support classification systems rather than for quantitative purposes. Usually, the resulting materials are analytically described and categorised into relevant classes for monitoring. The classification is primarily based on the substances that comprise the relevant CDW materials, facilitating in that way the separation of non-hazardous CDW materials from hazardous materials. From this perspective, the descriptive definitions play a critical role in decision-making with the aim of protecting the environment.

The definition proposed by Shen, et al. [54] can be considered to be representative of the descriptive definitions, as it clearly describes the basic types of building materials that constitute the CDW stream. This definition is listed in Table 1 along with other descriptive definitions. Although such definitions accurately describe the composition of the CDW stream, most of them are characterised by a high degree of generality and heterogeneity due to the different natures of materials' substances. For instance, Poon [55] defined CDW as a "mixture of inert and non-inert materials", including excavation waste [55], while Wang, Wu, Tam, and Zuo [53] exclude excavation soil from their CDW definition [53]. Furthermore, Tchobanoglous, et al. [56] defined CDW materials by including the words "relatively", "heterogeneous", and "various", which all etymologically refer to something that is not consistent [57] (p. 262).

Such generalities in definitions may lead to the formation of vague classes in the CDW stream with overlapping terminologies and eventually may cause a misinterpretation of the released waste data. For instance, variations regarding the definition of CDW materials have been found to be associated with poor waste data in Europe [58]. This problem is also evident in the United States and Australia and is related to the different perspectives based on which the local waste legislation and classification systems are generally developed $[2,19]$. As can be concluded, inconsistent CDW analytics and vague classification groups adversely impact the CEP as not all CDW materials are properly recorded for reuse, recycling, or recovery.

The third category involves CDW definitions that have been stated from an economic perspective. Table 1 also includes such definitions, and, as can be seen, it is a quite popular category [22,39-41,50,59-62]. These definitions consider CDW as unwanted materials after their first use on sites that do not have any added value for clients or for projects. Such a conceptual approach mainly supports the linear economic model rather than the 
CE [63]. Thus, the economic definitions usually embrace monetary terminology such as "material/equipment/labour wastage", "no residual value", non-added value", or "indirect costs", and other similar terms.

A plethora of different terms also exist in the economic CDW definitions. For instance, Skoyles [62] categorised CDW materials as "direct and indirect waste", which refer to material wastage and monetary loss, respectively. Koskela [22] also employed the term "indirect waste" to measure the inefficiency in the production and operation processes [22]. However, the terminology "non-value-adding activity" was introduced to underpin the measurement and minimisation of time delays and extra costs due to the storage and transportation of CDW materials. Conversely, the definitions stated by Alarcon [64] and Formoso, Isatto, and Hirota [23] focus on the minimisation both of "direct" and "indirect" waste in order to add value to the final product $[23,64]$.

Apart from "direct" and "indirect" waste, Nagapan, Rahman, and Asmi [60] defined CDW materials as "physical waste" derived from human or industrial activities that have zero added value [60]. Denzel et al. (2015) argued that waste in construction can be defined based on three attributes: "object, "effort", and "value". In particular, waste can be related to construction activities and the relevant outcome ("object of contemplation"), while the "effort" and "value" terms refer to the wasted time and value loss for the client/company/project, respectively [40].

As can be concluded, the economic definitions highlight that waste is mainly related to the inefficient use of resources during the implementation of a construction project. From that perspective, they solely embrace the economic dimension to support lean construction management, as stated by Denzer, Muenzl, Sonnabend, and Haghsheno [40]. Despite that, the economic definitions promote the disposal of CDW materials rather than their circularity. Even if the definition stated by Koskela [22] embraces the word "space", which has a spatial dimension, it is not used with the meaning of "proximity" to foster the circular economy; i.e., by limiting the transportation of CDW materials only within local areas.

\subsection{Legislative Definitions of CDW Materials}

This subsection presents the results regarding the legal definitions associated with CDW materials in Europe, the United States, Asia, and Australia. The literature shows that the legislative definitions in the targeted continents/countries are similar to the descriptive scholarly definitions discussed previously. That means that they describe the components that make up the CDW stream to support the developed classification systems. However, there are many discrepancies that exist in the jurisdictional definitions, which are mainly related to the different waste management legislation approaches. Such discrepancies prevent the growth of the CE.

In 2008, the European Commission (EC) launched the Directive 2008/98/EC (Directive) to overcome the inconsistencies in definitions and underpin the circular economy within the E.U. member countries $[65,66]$. The Directive constitutes the overarching waste legislative framework in the European Union, which defines the waste stream, determines the end of life of waste materials, and sets recycling targets [67]. In particular, Article 3 of the Directive defines waste as "any substance or object which the holder discards or intends or is required to discard" [66].

As can be seen, the definition has been stated from a general rather than a holistic perspective through which the socio-economic and environmental impacts of the waste stream can be controlled [65]. Due to this generality and vagueness of the existing definition, bulky CDW materials-e.g., asphalt and track ballast—are not included in waste analytics [68]. To address the definition gap and improve the CDW logistics, the European Commission (EU Commission) launched the "European CDW Management Protocol" (Protocol) in 2016 [69]. 
Specifically, the Protocol defines CDW materials as "any waste generated in the activities of companies belonging to the construction sector and included in category 17 of the European List of Waste" [69]. The definition is linked to the European Waste Catalogue (EWC) or otherwise stated as the List of Waste (LoW). The latter is a hierarchical taxonomy system established by the EU Commission (Decision 2000/532/EC), in which CDW materials are included in Chapter 17 [69,70]. In doing so, a transparent and standard definitional terminology regarding CDW materials is achieved.

The Directive 2008/98/EC was amended in 2018 to further clarify the existing waste definitions and promote the sustainable use of resources by introducing new terminology such as "material recovery" and "backfilling" [71]. Although the new Directive 2018/851/EC promotes the CE, it lacks a definition of the recycling potential of the entire CDW stream. In particular, the amendments mainly involve the embracement of the "do-it-yourself" category, which may include materials from construction and demolition waste activities [71].

In the United States, the Resource Conservation and Recovery Act 1975 manages both hazardous and non-hazardous waste [20]. CDW materials belong to the non-hazardous solid waste stream. They are defined as "waste that is generated from the construction, renovation, repair, and demolition of structures such as residential and commercial buildings, roads, and bridges" [72] (p. 169). They are also defined in "Title 40 of the Code of Federal Regulations", in particular in Part 243, Section 243.101 as follows: "CDW means the waste building materials, packaging, and rubble resulting from construction, remodelling, repair, and demolition operations on pavements, houses, commercial buildings, and other structures" [73]. Both definitions are developed in the same fashion with the descriptive scholarly definitions, which lack a conceptualisation of the CEP.

CDW materials are also not defined in a comprehensive way in Asia. In Japan, they are described as "construction by-products", consisting of construction aggregates and construction waste; the former can be directly reused without any further procedure, while the latter concerns waste that can be recycled or may be hazardous [74]. In China, the Ministry of Housing and Urban-Rural Development classifies CDW materials as "urban solid waste" and defines them according to the type of project and based on the "Regulation of Urban Construction Waste" [75]. Furthermore, in India, the Ministry of Environment, Forest, and Climate Change defines CDW based on the Solid Waste Management Rules 2015 as "waste consisting of building materials, debris, and rubble resulting from construction, remodelling, restoration, and destruction of any civil construction" [76].

Despite the fact that most Asian countries have set high recycling targets $(80-90 \%)$ in their waste management strategies [37] (p. 317), such general definitions are not suitable to foster sustainable waste management within the Asian continent. That is because they do not distinguish waste from recyclable materials. Furthermore, they do not define the non-hazardous materials as resources; therefore, they cannot advance the circular economy. This gap needs to be bridged urgently, as more than 1 billion tons of CDW materials are disposed of annually in landfills in China alone [5].

Definitions from a common and holistic approach regarding CDW materials are also absent in Australia. In particular, CDW materials are defined in Australia at a national level according to the "2018 National Waste Policy (NWP)" [77]. Table 2 lists the relevant legislative definitions of CDW materials that exist at a national level in Australia along with the other definitions in China and India as well as in the European Union and the United States that were mentioned previously. As can be seen from Table 2, they are defined in a general fashion like the United States. This simplicity in definitions at a national level does not correspond to the significance of the CDW material in Australia, as the country generates more than 20 million tons annually $[9,78]$. 
Table 2. Legislative definitions ${ }^{1}$ for CDW in Australia, China, the European Union, India, the United Nations, and the United States.

\begin{tabular}{|c|c|}
\hline Country & $\begin{array}{l}\text { CDW } \\
\text { Definition }\end{array}$ \\
\hline Australia & $\begin{array}{l}\text { "Waste produced by demolition and building activities, including road and rail construction and } \\
\text { maintenance, and land excavation associated with construction activities" }\end{array}$ \\
\hline China & $\begin{array}{l}\text { "Waste soil, waste material, and other waste generated during construction, reconstruction, expansion } \\
\text { works, and demolition of various types of buildings, building structures, and pipe networks by building } \\
\text { units and construction contractors" }\end{array}$ \\
\hline European Union & $\begin{array}{l}\text { "Any waste generated in the activities of companies belonging to the construction sector and included in } \\
\text { category } 17 \text { of the LoW (Decision 2000/532/EC)" }\end{array}$ \\
\hline India & $\begin{array}{l}\text { "Waste consisting of building materials, debris, and rubble resulting from construction, re-modelling, } \\
\text { restoration, and destruction of any civil construction" }\end{array}$ \\
\hline $\begin{array}{c}\text { UN } \\
\text { (Rio Agenda 1992) }\end{array}$ & $\begin{array}{l}\text { "Solid wastes including all domestic refuse and non-hazardous wastes such as commercial and } \\
\text { institutional wastes, street sweepings, and construction debris" }\end{array}$ \\
\hline USA & $\begin{array}{l}\text { "Waste that is generated from the construction, renovation, repair, and demolition of structures such as } \\
\text { residential and commercial buildings, roads, and bridges" }\end{array}$ \\
\hline
\end{tabular}

It is worth mentioning that the 2018 NWP is an updated version of the initial 2009 Australian NWP, "Less Waste More Resources", that ameliorates the data inconsistencies in the waste stream and reinforces resource recovery in Australia [79]. Despite the fact that the Australian states and territories have not yet adopted a uniform definition regarding the CDW stream, as Strategy 4 of the 2018 NWP advocates [19], Ramsay and Associates [80] argued that there is a degree of subjectivity in the interpretation of the term "CDW", which depends on the needs of each local government. The existing dissimilarities in the jurisdictional definitions may lead to different classification groups, harming the circular economy significantly [19].

Table 3 presents the key concepts of the jurisdictional definitions for CDW materials in Australia, where the disparities are evident. For instance, in South Australia, the definitional term "Foreign Material" is used to classify CDW materials such as timber, plastic, and insulation. The same types of building waste can be found as "Solid Inert Waste" in other Australian states; however, in Tasmania, the treated timber is not defined as "Solid Inert Waste" [81]. Other examples of definitional variations concern the "excavated soil" and "stockpile materials" as a different terminology is used among the Australian jurisdictions, such as "Clean Fill", "Fill", or "Daily Cover" [19,80,81]. However, in Tasmania and Western Australia, these types of materials are not recorded as waste at all [77].

Shooshtarian, Maqsood, Khalfan, Wong, and Yang [78] argued that only New South Wales (NSW) and Western Australia (WA) have established comprehensive definitions for CDW materials so far [78]. Although both definitions are highly descriptive and technically detailed, they differ from each other significantly. This variation is also evident among the other Australian jurisdictions, as mentioned previously. Therefore, it is of paramount importance to establish a uniform definition for the CDW stream across Australian jurisdictions to ameliorate the disparities in classification groups and support the circular economy [77] (p. 101).

Recently, the 2020 NWP developed seven circular economy indicators based on the MFA [77]. The "Recycled Content (RC)", "Collection Efficiency (CE)", and "Sorting Efficiency (SE)" [77] (p. 35) indicators are related in this study. In particular, the RC is defined as the "secondary sourced material divided by consumption", the CE as "discarded materials collected for recovery divided by total discarded materials entering the waste system", and the SE is defined as "materials collected for sorting divided by materials sent to reprocessing" [77] (p. 35). This is a positive step to support the circular economy strategies set by Australian local governments. 
However, the current definitions for CDW materials across the Australian jurisdictions cannot support these metric indicators as their scope is not related to the circular economy. Therefore, conceptualising the circular economy potential of CDW materials is of great importance for the Australian construction industry as it may help to divert millions of tons of material resources from landfills, which then can be sorted and measured accordingly to support the circular economy indicators. The significance of this concept is underpinned by the high landfilling rate in Australia (27\%), which means that approximately 5.5 million tons of material resource potential is wasted annually, threatening the space in the major Australian landfills $[9,82]$.

Table 3. CDW definitions ${ }^{1}$ in the Australian jurisdictions.

\begin{tabular}{|c|c|}
\hline Jurisdiction & Key Concepts of the CDW Definition \\
\hline $\begin{array}{l}\text { Australian Capital } \\
\text { Territory (ACT) }\end{array}$ & $\begin{array}{l}\text { The "non-mixed and free-from-asbestos resulting materials" (i.e., bricks, concrete, paper, plastics, glass, } \\
\text { metal, and timber) in different types of projects such as roads, bridges, dams, tunnels, railways, and } \\
\text { airports. Not related to the circular economy. }\end{array}$ \\
\hline $\begin{array}{l}\text { New South Wales } \\
\quad(\text { NSW) }\end{array}$ & $\begin{array}{l}\text { The "unsegregated material", which is free from asbestos and excludes soil and timber treated with } \\
\text { chemicals. CDW may result from } \\
\text { (i) demolition, erection, construction, refurbishment, or alteration of buildings other than chemical works, } \\
\text { mineral processing works, container reconditioning works, or waste treatment facilities; or } \\
\text { (ii) the construction, replacement, repair, or alteration of infrastructure development such as roads, tunnels, } \\
\text { sewage, water, electricity, telecommunications, and airports }\end{array}$ \\
\hline $\begin{array}{l}\text { Northern Territory } \\
\qquad(\mathrm{NT})\end{array}$ & $\begin{array}{l}\text { The solid waste sourced from construction and demolition works, which may include excavated natural } \\
\text { soil and asphalt waste }\end{array}$ \\
\hline $\begin{array}{l}\text { Queensland } \\
\text { (QLD) }\end{array}$ & $\begin{array}{l}\text { The "non-putrescible waste material" such as timber, clean soil, concrete, asphalt, plasterboard, steel, } \\
\text { bricks, ceramic and clay tiles, and aluminium which may derive from any building, refurbishing, } \\
\text { renovating, or demolishing infrastructure works (e.g., roads, bridges, and docks). }\end{array}$ \\
\hline $\begin{array}{l}\text { South Australia } \\
\qquad(\mathrm{SA})^{1}\end{array}$ & $\begin{array}{l}\text { The "solid inert component of the waste stream" (e.g., bricks, concrete, tiles and ceramics, steel, and inert } \\
\text { soils) arising from the construction, demolition, or refurbishment of buildings or infrastructure. The } \\
\text { definition distinguishes CDW from Municipal Solid Waste, Commercial and Industrial Waste, Listed } \\
\text { Waste, Hazardous Waste, and Radioactive Waste. It also defines plastics, electrical wiring, timber, paper, } \\
\text { insulation, tins, packaging, and green waste as foreign material. }\end{array}$ \\
\hline $\begin{array}{l}\text { Tasmania } \\
\text { (TAS) }\end{array}$ & $\begin{array}{l}\text { The "solid inert materials" such as bricks, concrete, glass, plastics, metal, and timber that result from } \\
\text { building and demolition works. However, treated timber is excluded. }\end{array}$ \\
\hline $\begin{array}{l}\text { Victoria } \\
\text { (VIC) }\end{array}$ & $\begin{array}{l}\text { The "solid inert waste from an industrial source" (i.e., concrete, bricks, dry timber, plastic, glass, metals, } \\
\text { bitumen). However, soil, sand and rock are defined as "Clean fill". }\end{array}$ \\
\hline
\end{tabular}

Materials that are not mixed with green and food waste and are free of asbestos. Such materials are bricks,

Western Australia concrete, plastics, glass, metal, and timber that should be recovered from the CDW as well as small

(WA) quantities of paper. CDW may arise from the construction, refurbishment, or demolition of buildings, or infrastructure-type development such as roads, bridges, dams, tunnels, railways, and airports.

${ }^{1}$ Sources: $[80,81,83-86]$.

\section{Discussions}

\subsection{The Lack of a Holistic Conceptual Approach Regarding CDW Materials Hampers the Circular Economy}

The majority of the existing CDW definitions in the scholarly literature integrate different terminologies, which mainly depend on the scope for which the definition is developed. As a result, definitions can be grouped into three categories: (i) quantitative definitions, which aim to address the need for estimating the amount of material wastage; (ii) descriptive definitions, which seek to clarify the origin and types of building materials to support the relevant CDW classification systems; and (iii) economic definitions, which embrace monetary terms to define CDW either as material, labour, or equipment wastage.

From an overall perspective, the discussed definitions encapsulate a common but also a negative conceptual approach regarding CDW materials. In particular, the adverse intent of the current definitions is generally related to the inefficient use of materials, equipment, 
and labour. This approach aligns with the conceptual definition of the waste stream, as the term "wastum" was also used to describe a "refuse material" or "expenditure" during the Industrial Revolution [38] (p. 200). Therefore, they agree with the themes that historical definitions put in place 500 years ago.

The literature shows that the rationale in the current CDW definition hampers, rather than supports, the circular economy. The dominant role of the obsolete linear economic model of "make-consume-waste" [87] is evident in the construction industry as the industry is responsible for the consumption of vast quantities of materials and the generation of billions of tons of CDW materials annually [37]. Therefore, it is essential to reconsider CDW materials as valuable resources that can advance the circular economy and promote the environmental sustainability of construction projects $[6,88,89]$.

Very few of the developed definitions directly advocate for the circular economy. Such definitions were given by Skoyles and Skoyles [49], The Hong Kong Polytechnic School in 1993, and by Muhwezi, et al. [90], which are analytically listed in Table 1. In particular, the last two definitions strongly support the circular economy as they clearly promote the reuse and recycling process. However, they both lack a holistic approach as they do not embrace the five dimensions of the CDW phenomenon, as mentioned in the Introduction section.

In particular, they lack an integration of the spatial and temporal dimensions, such as the proximity factor of "location" and the "materials' lifecycle", respectively. As a result, these definitions cannot foster or force the transportation of the generated CDW materials to the nearest facilities for treatment in order to mitigate their transportation impact. By doing so, the carbon footprint of CDW materials can be reduced significantly throughout their lifecycle.

This gap is evident in CDW definitions as most of them mainly deal with the CDW material within project boundaries, ignoring the spatial dimension. The latter is not only associated with the conceptual definition of waste as explained in the Introduction section but also inherently related to CDW management as the resulting materials need to be transported across different venues. Despite this, it has rarely been integrated into the contemporary definitions. Those definitions that have already embraced it are not related to the circular economy. For instance, Koskela's definition [22] encompasses the word "space", but that word is used to support lean construction management as it is considered to be another type of resource along with time and cost [40].

Furthermore, the temporal dimension is absent from the current CDW definitions as they do not involve any terminology that considers the carbon footprint of CDW materials throughout their lifespan. This lifecycle impact comprises the carbon dioxide emissions released from the transportation and treatment phases of CDW materials, apart from their materially embodied carbon [91]. Therefore, a modern conceptualisation of the circular economy potential of CDW materials should aim to mitigate their carbon impact throughout their lifespan. This can be achieved by fostering the allocation of the resulting materials to the closest resource centres for recycling/recovery or to any proxy construction sites, material banks, and transfer stations for reuse and storage, respectively [6].

On the other hand, the legislative definitions are mainly related to the category of the "descriptive definitions" as they describe in detail the composition and origin of CDW materials. However, most of them are characterised by generalities and a complicated description with an overlapping terminology. In particular, the jurisdictional definitions in Australia present such inconsistencies, which prevent the comprehensive classification of CDW materials, thus impacting the waste analytics at a national level $[19,77]$. Furthermore, their scope lacks the consideration of the circular economy; thus, they cannot support the circular economy indicators recently established by the Australian Government.

Similarly, in the United States, discrepancies in the definitions exist among states, which are mainly related to the dominant role of the local waste management laws [92,93]. Furthermore, the definitions in China and India are established in a general manner that urges the use of a complex legislative framework to directly manage the CDW stream and support the circular economy $[20,94]$. Conversely, the definition included in the "EU 
CDW Management Protocol" promotes the circularity of materials in a more effective way than the aforementioned countries, as it is directly related to the European taxonomy system (LoW).

Although the definition included in the Protocol enables the consistent classification of CDW materials within the E.U. member states, eventually underpinning the circular economy, it solely depends on the technicality of the pre-defined CDW categories of the LoW. This technicality relates to the coding of the categories in which CDW materials are classified. It also reflects the scope of the LoW, which is effectively used to classify the CDW stream according to the types of the resulting materials rather than to foster the circular economy. Additionally, the LoW does not consider the lifecycle of materials; therefore, the Protocol's definition still lacks a holistic conceptual perspective for CDW materials.

In summary, the current CDW definitions do not advance the circular economy and environmental sustainability in the construction industry as they were not developed based on a multidimensional approach (a holistic perspective) that considers the potential of CDW materials in the circular economy. There are three main reasons for this gap in the literature:

(a) The extant definitions do not take into account the dynamic nature of CDW material. Thus, they fail to embrace the spatial and temporal dimensions to control materials' lifecycle impacts. They mainly consider a one-dimensional conceptual approach for CDW materials that supports quantitative, economic, or classification needs. However, this is a linear conceptual approach that does not match with the dynamic nature of CDW materials and their potential for circularity throughout their lifespan.

(b) Most of the current definitions highlight the negative aspect of CDW materials as they define them as "unwanted materials" or "materials with nil value" rather than as a material resource for the circular economy. Such a conceptual approach promotes the landfilling of materials with the aim of advocating the linear economy instead of environmental sustainability in the construction industry.

(c) No standard terminology has yet been set for the concept of the circular economy potential in the CDW management literature. Additionally, both scholarly and legislative definitions are highly descriptive, presenting generalities, disparities, or an overlapping terminology. Such inconsistencies affect the circular economy and require robust data.

Therefore, there is an urgent need to conceptualise the circular economy potential of CDW materials with the aim of advocating for the circular economy and sustainability in the built environment.

\subsection{Towards Conceptualising the Circular Economy Potential of CDW Materials}

As mentioned previously, the existing CDW definitions were mainly developed from an environmental or economic perspective. However, CDW is a dynamic phenomenon that eventuates over time and across various locations. Therefore, the spatial and temporal dimensions should be considered in the conceptualisation of the circular economy potential of CDW materials to help the local economy maximise the socio-economic and environmental benefits of this new concept. The importance of embracing the spatial dimension in CDW management can also be seen in the "EU CDW management protocol", as the term "location" constitutes the sixth of its eight principles [69]. The Protocol considers the distance travelled of the allocated CDW quantities in order to improve CDW logistics within member countries.

By improving CDW logistics with the aim of supporting the "3Re" policy (reuse, recycling, recovery), green domestic businesses can further benefit or other new benefits can be developed from this intense interaction. To support such "3Re" interactions, we need to conceptualise the circular economy potential of CDW materials from a holistic perspective, which is based on a multidimensional approach. The latter may include spatial and temporal terms such as "geographical proximity" and "lifecycle", or other key words such as "material", "3Re policy", or "circular economy". In this way, the gap in the 
literature can be bridged, leading to a possible transformation of the current mindset in the industry regarding CDW materials.

This transformation should involve a shift from the use of the term "waste" to the adoption of the term "material" and from the meaning of "zero added value" to establishing a "resource" meaning instead. Even though the word "material" is included in the majority of waste definitions, it has widely been used in an adverse manner; e.g., "material wastage", "unwanted material", "damaged material", or "materials with no added value". Such terminologies in CDW definitions support the linear economic model rather than the circular economy.

This study conceptualises the circular economy potential of the non-hazardous CDW materials by considering five dimensions (in a holistic approach)—social, economic, environmental, spatial, and temporal - to maximise their diversion from landfills with the aim of advancing the circular economy and mitigating their lifecycle carbon footprint. The statement below highlights this conceptualisation:

"The circular economy potential of construction and demolition resources (CEPCDR) is the resulting mass of non-hazardous building materials that are generated due to construction and demolition activities and can be potentially used as by-products to promote environmental sustainability considering the geographical proximity of resource facilities and the lifecycle carbon footprint of making and transporting the by-products".

As can be seen, by employing terms such as "resulting mass" and "resource", the aforementioned statement emphasises that non-hazardous CDW materials are still valuable resources for the circular economy after their first usage on-site. Thereby, the CEPCDR contributes to the diversion of CDW materials from landfills. As a result, the CEPCDR should be measured in kilograms or tons to standardise the measurement units, thus addressing inconsistencies in CDW analytics. The current variations in definitions and classifications of CDW materials have led to poor CDW analytics that cannot empower the circular economy [6]. Conversely, the concept of the CEPCDR can prevent losses for the circular economy by recording any reusable/recyclable CDW materials as CEPCDRs in a consistent way with the aim of enhancing CDW analytics. This would be highly valued, as providing robust data from the CDW stream is vital to advancing the circular economy effectively.

Furthermore, by conceptualising the CEPCDR from a holistic perspective, the lifecycle impact of materials (cradle-to-cradle boundaries or C2C) can be mitigated. The latter is comprised of the materially embodied carbon and the carbon dioxide emissions from transportation and treatment $[53,95]$. To mitigate the C2C emissions-specifically, those related to the transportation and treatment phase of CDW materials-the CEPCDR integrates the spatial dimension of "geographical proximity". This dimension refers to the location of construction sites with regard to the recycling facilities, resource recovery centres, material banks, or transfer stations. In doing so, stakeholders are forced to transport the CEPCDR to the closest facilities for treatment or storage by finding the optimal distance between the site and the relevant facilities each time. As a result, the transportation impact can be reduced significantly.

Apart from that, the proposed CEPCDR advocates for the mitigation of the $\mathrm{CO}_{2}$ emissions associated with the treatment of materials. In particular, by excluding the landfilling option from the treatment scenarios, the proposed concept fosters the diversion of the CEPCDR from landfills, thus promoting reuse, recycling, and recovery. Thereby, the $\mathrm{CO}_{2}$ emissions released from the $3 \mathrm{Re}$ process are significantly lower than that those from landfilling, thus contributing to the mitigation of global warming, which affects the construction industry. The latter is of great importance to the Australian government, which must reduce the carbon footprint of its major industrial sectors, including the construction sector, by $26 \%$ to $28 \%$ by 2030 compared to 2005 levels [95]. 


\section{Conclusions}

This study examined the scholarly and legislative definitions of CDW materials and whether or not their conceptual approach may advance the circular economy and sustainability in the built environment. It was found that CDW definitions can be categorised based on their embraced terminology and scope into three main groups: quantitative, descriptive, and economic definitions. The quantitative definitions usually address quantitative needs; e.g., the need to estimate the volume or mass of the generated CDW materials on sites. The descriptive CDW definitions were mainly developed to support waste classification systems, while the economic definitions are generally related to lean production management.

Most of the definitions do not conceptualise CDW materials as having valuable recycling potential for the circular economy. Although the quantitative and descriptive definitions can be used to accurately measure and classify the resultant amount of CDW materials to eventually support the circular economy, they present inconsistencies. In particular, the quantitative definitions do not standardise the metric units of measurements (e.g., cubic meters or kilograms), while the descriptive definitions present generalities or dissimilar terminologies, which may lead to vague classification groups. Such inconsistencies adversely impact the circular economy, which requires robust data.

On the other hand, most of the economic definitions describe CDW as unwanted materials with zero added value for projects and clients. This conceptual approach promotes the disposal of reusable or recyclable CDW materials into landfills with the aim of supporting the linear economy. Therefore, the extant definitions mainly focus on the negative aspect of CDW materials, which reflects their social, economic, and environmental impacts. However, these impacts can be ameliorated if we consider the spatial and temporal dimensions, which are associated with the dynamic nature of CDW materials.

Specifically, these two dimensions are related to the $\mathrm{CO}_{2}$ emissions released from the transportation and treatment phases of CDW materials. The current definitions fail to embrace these dimensions to mitigate these impacts with the aim of supporting environmental sustainability in the construction industry. Furthermore, the discussed definitions do not emphasise that CDW materials remain materials after their first use on-site, which would promote the " $3 R^{2}$ " policy. As a result, they cannot promote a holistic managerial approach for the CDW stream in waste legislation and support the relevant CDW management strategies.

In summary, this study conceptualises the circular economy potential of CDW materials (CEPCDRs) from a holistic perspective, which encompasses five dimensions-social, economic, environmental, spatial, and temporal-with the aim of enhancing the circular economy and sustainability in the built environment. In doing so, the study bridges the relevant gap in the literature in a novel way, advancing the theories of CDW management.

Understanding the circular economy potential of CDW materials has important implications for societies and governmental practices. This new concept establishes that CDW materials are a valuable resource for the circular economy and enables the maximisation of their diversion from landfills. The landfilling option may be excluded to maximise the benefits for the local community by creating new jobs through the growth of recycling and other types of green businesses. The environment can be improved by mitigating the carbon footprint of the CDW stream, thus enhancing social justice and the resilience of local communities. This work may also contribute to transforming the mindset in the industry as it promotes the socio-economic and environmental benefits associated with CDW materials instead of focusing on their negative impacts. Lastly, the study seeks to drive future research in measuring the CEPCDR.

\section{Limitations}

Three major limitations governing the current study should be noted: the first concerns the absence of primary research data; the second is related to the scarcity of the secondary data retrieved from the literature regarding CDW materials; and, finally, the third refers 
to the geographical domain of the current research, which focuses on Australia, China, Europe, India, and the United States.

Author Contributions: Conceptualization: V.P., K.L. and Y.F.; methodology: V.P., K.L.,Y.F. and P.Z.; software: V.P.; validation: V.P., K.L., R.C., P.P., Y.F. and P.Z.; formal analysis: V.P.; investigation: V.P.; writing—original draft preparation: V.P.; writing—review and editing: V.P., K.L., Y.F., P.Z., R.C. and P.P.; visualization: V.P., supervision of PhD research: K.L., R.C., P.P. All authors have read and agreed to the published version of the manuscript.

Funding: This research is a part of a PhD study that was funded by the Commonwealth of Australia (CRICOS Provider Number 00121B) via the University of South Australia, grant code and number: USAPA 228182.

Institutional Review Board Statement: Not applicable.

Informed Consent Statement: Not applicable.

Data Availability Statement: Not applicable.

Acknowledgments: I would like to thank Evdokia Papastamouli for her voluntary prof editing services of this manuscript. Also, I would like to thank MDPI for their excellent communication, professionalism and support from the beginning until the publication of this manuscript.

Conflicts of Interest: The authors declare no conflict of interest. The funders had no role in the design of the study; in the collection, analyses, or interpretation of data; in the writing of the manuscript; or in the decision to publish the results.

\section{References}

1. Chileshe, N.; Rameezdeen, R.; Hosseini, M.R.; Martek, I.; Li, H.X.; Panjehbashi-Aghdam, P. Factors driving the implementation of reverse logistics: A quantified model for the construction industry. Waste Manag. 2018, 79, 48-57. [CrossRef] [PubMed]

2. Tam, V.W.-Y.; Lu, W. Construction Waste Management Profiles, Practices, and Performance: A Cross-Jurisdictional Analysis in Four Countries. Sustainability 2016, 8, 190. [CrossRef]

3. Duan, H.; Miller, T.R.; Liu, G.; Tam, V.W. Construction debris becomes growing concern of growing cities. Waste Manag. 2019, 83, 1-5. [CrossRef] [PubMed]

4. Ginga, C.P.; Ongpeng, J.M.C.; Daly, M.; Klarissa, M. Circular economy on construction and demolition waste: A literature review on material recovery and production. Materials 2020, 13, 2970. [CrossRef]

5. Huang, B.; Wang, X.; Kua, H.; Geng, Y.; Bleischwitz, R.; Ren, J. Construction, and demolition waste management in China through the 3R principle. Resour. Conserv. Recycl. 2018, 129, 36-44. [CrossRef]

6. Papastamoulis, V.; London, K.; Crocker, R.; Patias, P. Transforming Construction Waste Analytics to Support Circular Economy and Carbon Footprint Reduction: Construction Waste Mapping Protocol CDWiMaP. In Handbook of Research on Driving Transformational Change in the Digital Built Environment; IGI Global: Hershey, PA, USA, 2021; Volume 3, pp. 232-264. [CrossRef]

7. Kabirifar, K.; Mojtahedi, M.; Wang, C.; Tam, V.W.Y. Construction and demolition waste management contributing factors coupled with reduce, reuse, and recycle strategies for effective waste management: A review. J. Clean. Prod. 2020, 263, 121265. [CrossRef]

8. Aslam, M.S.; Huang, B.; Cui, L. Review of construction and demolition waste management in China and USA. J. Environ. Manag. 2020, 264, 110445. [CrossRef]

9. Ratnasabapathy, S.; Alashwal, A.; Perera, S. Investigation of waste diversion rates in the construction and demolition sector in Australia. Built Environ. Proj. Asset Manag. 2021, 11, 427-439. [CrossRef]

10. Nunes, K.; Mahler, C. Comparison of construction and demolition waste management between Brazil, European Union, and USA. Waste Manag. Res. 2020, 38, 415-422. [CrossRef]

11. Jain, S.; Singhal, S.; Jain, N.K. Construction, and demolition waste generation in cities in India: An integrated approach. Int. J. Sustain. Eng. 2019, 12, 333-340. [CrossRef]

12. Ma, M.; Tam, V.W.; Le, K.N.; Li, W. Challenges in current construction and demolition waste recycling: A China study. Waste Manag. 2020, 118, 610-625. [CrossRef] [PubMed]

13. Yazdani, M.; Kabirifar, K.; Frimpong, B.E.; Shariati, M.; Mirmozaffari, M.; Boskabadi, A. Improving construction and demolition waste collection service in an urban area using a simheuristic approach: A case study in Sydney, Australia. J. Clean. Prod. 2021, 280, 124138. [CrossRef]

14. Ulubeyli, S.; Kazaz, A.; Arslan, V. Construction and Demolition Waste Recycling Plants Revisited: Management Issues. Procedia Eng. 2017, 172, 1190-1197. [CrossRef]

15. Wu, H.; Zuo, J.; Yuan, H.; Zillante, G.; Wang, J. Cross-regional mobility of construction and demolition waste in Australia: An exploratory study. Resour. Conserv. Recycl. 2020, 156, 104710. [CrossRef]

16. Zhang, N.; Zheng, L.; Duan, H.; Yin, F.; Li, J.; Niu, Y. Differences of methods to quantify construction and demolition waste for less developed but fast-growing countries: China as a case study. Environ. Sci. Pollut. Res. 2019, 26, 25513-25525. [CrossRef] 
17. Kabirifar, K.; Mojtahedi, M.; Wang, C.C. A Systematic Review of Construction and Demolition Waste Management in Australia: Current Practices and Challenges. Recycling 2021, 6, 34. [CrossRef]

18. Ruiz, L.A.L.; Ramón, X.R.; Domingo, S.G. The circular economy in the construction and demolition waste sector-A review and an integrative model approach. J. Clean. Prod. 2020, 248, 119238. [CrossRef]

19. Pickin, J.; Randell, P.; Latimer, G. Improving National Waste Data and Reporting; Blue Environment Pty Ltd., ASCEND Waste \& Environment, Randell Environmental Consulting, Department of the Environment and Energy: Docklands, VIC, Australia, 2018; pp. 1-68.

20. Wen, X.; Luo, Q.; Hu, H.; Wang, N.; Chen, Y.; Jin, J.; Hao, Y.; Xu, G.; Li, F.; Fang, W. Comparison research on waste classification between China and the EU, Japan, and the USA. J. Mater. Cycles Waste Manag. 2014, 16, 321-334. [CrossRef]

21. Skoyles, E.R.; Hussey, H.J. Wastage of Materials on Building Sites; Current Paper 74/CP44; Building Research Establishment: Garston, UK, 1974.

22. Koskela, L. Application of the New Production Philosophy to Construction (TR072); Stanford University: Stanford, CA, USA, 1992.

23. Formoso, C.; Isatto, E.L.; Hirota, E.H. Method for Waste Control. In the Building Industry. In Proceedings of the 7th Annual Conference of the International Group for Lean Construction, University of California, Berkeley, CA, USA, 26-28 July 1999; pp. 325-334.

24. Tam, V.W.Y.; Shen, L.Y.; Tam, C.M. Assessing the levels of material wastage affected by sub-contracting relationships and project types with their correlations. Build. Environ. 2007, 42, 1471-1477. [CrossRef]

25. Menegaki, M.; Damigos, D. A review on current situation and challenges of construction and demolition waste management. Curr. Opin. Green Sustain. Chem. 2018, 13, 8-15. [CrossRef]

26. Kourmpanis, B.; Papadopoulos, A.; Moustakas, K.; Stylianou, M.; Haralambous, K.J.; Loizidou, M. Preliminary study for the management of construction and demolition waste. Waste Manag. Res. 2008, 26, 267-275. [CrossRef]

27. Fatta, D.; Papadopoulos, A.; Avramikos, E.; Sgourou, E.; Moustakas, K.; Kourmoussis, F.; Mentzis, A.; Loizidou, M. Generation and management of construction and demolition waste in Greece-An existing challenge. Resour. Conserv. Recycl. 2003, 40, 81-91. [CrossRef]

28. Guerra, B.C.; Leite, F. Circular economy in the construction industry: An overview of United States stakeholders' awareness, major challenges, and enablers. Resour. Conserv. Recycl. 2021, 170, 105617. [CrossRef]

29. Joensuu, T.; Edelman, H.; Saari, A. Circular economy practices in the built environment. J. Clean. Prod. 2020, $276,124215$. [CrossRef]

30. Schröder, P.; Lemille, A.; Desmond, P. Making the circular economy work for human development. Resour. Conserv. Recycl. 2020, 156, 104686. [CrossRef]

31. Tisserant, A.; Pauliuk, S.; Merciai, S.; Schmidt, J.; Fry, J.; Wood, R.; Tukker, A. Solid Waste and the Circular Economy: A Global Analysis of Waste Treatment and Waste Footprints. J. Ind. Ecol. 2017, 21, 628-640. [CrossRef]

32. Ghisellini, P.; Ripa, M.; Ulgiati, S. Exploring environmental and economic costs and benefits of a circular economy approach to the construction and demolition sector. A literature review. J. Clean. Prod. 2018, 178, 618-643. [CrossRef]

33. Nobre, G.C.; Tavares, E. The quest for a circular economy final definition: A scientific perspective. J. Clean. Prod. 2021, $314,127973$. [CrossRef]

34. Tazi, N.; Idir, R.; Ben Fraj, A. Towards achieving circularity in residential building materials: Potential stock, locks, and opportunities. J. Clean. Prod. 2021, 281, 124489. [CrossRef]

35. Lederer, J.; Gassner, A.; Kleemann, F.; Fellner, J. Potentials for a circular economy of mineral construction materials and demolition waste in urban areas: A case study from Vienna. Resour. Conserv. Recycl. 2020, 161, 104942. [CrossRef]

36. Hoang, N.H.; Ishigaki, T.; Kubota, R.; Yamada, M.; Kawamoto, K. A review of construction and demolition waste management in Southeast Asia. J. Mater. Cycles Waste Manag. 2020, 22, 315-325. [CrossRef]

37. Barles, S. History of waste management and the social and cultural representations of waste. In The Basic Environmental History; Springer: Berlin/Heidelberg, Germany, 2014; pp. 199-226.

38. Formoso, C.; Soibelman, L.; de Cesare, C.; Isatto, E.L. Material Waste in Building Industry: Main Causes and Prevention. J. Constr Eng. Manag. 2002, 128, 316-325. [CrossRef]

39. Denzer, M.; Muenzl, N.; Sonnabend, F.A.; Haghsheno, S. Analysis of definitions and quantification of waste in construction. In Proceedings of the 23rd Annual Conference of the International Group for Lean Construction, IGLC 2015, Perth, Australia, 29-31 July 2015; pp. 723-732.

40. Ekanayake, L.L.; Ofori, G. Building waste assessment score: Design-based tool. Build. Environ. 2004, 39, 851-861. [CrossRef]

41. Alcayaga, A.; Wiener, M.; Hansen, E.G. Towards a framework of smart-circular systems: An integrative literature review. J. Clean. Prod. 2019, 221, 622-634. [CrossRef]

42. Martín-Martín, A.; Orduna-Malea, E.; Thelwall, M.; Delgado López-Cózar, E. Google Scholar, Web of Science, and Scopus: A systematic comparison of citations in 252 subject categories. J. Informetr. 2018, 12, 1160-1177. [CrossRef]

43. Martin, G.; Ozieranski, P.; Leslie, M.; Dixon-Woods, M. How not to waste a crisis: A qualitative study of problem definition and its consequences in three hospitals. J. Health Serv. Res. Policy 2019, 24, 145-154. [CrossRef] [PubMed]

44. UNEP; IETC. Agenda 21; United Nations Environment Programme, International Environmental Technology Centre: Rio de Janerio, Brazil, 2002; pp. 1-351. 
45. du Plessis, C.; Adebayo, A.; Ebohon, J.; Irurah, D.; Rwelamila, P.; Hassan, A.S.; Laul, A.; Shah, K.; Agopyan, V.; de Arruda, M.P.; et al. Agenda 21 for Sustainable Construction in Developing Countries. A Discussion Document; The International Council for Research and Innovation in Building and Construction (CIB), United Nations Environment Programme (UNEP), International Environmental Technology Centre (IECT): Pretoria, South Africa, 2002; pp. 1-83.

46. Shen, L.; Tam, V.; Tam, C.; Ho, S. Material wastage in construction activities-A Hong Kong survey. In Proceedings of the First CIB-W107 International Conference-Creating a Sustainable Construction Industry in Developing Countries, Pretoria, South Africa, 11-13 November 2002; pp. 125-131.

47. Roche, T.; Hegarty, S. Best Practice Guidelines on the Preparation of Waste Management Plans for Construction and Demolition Projects; Department of the Environment, Community and Local Government: Dublin, Ireland, 2006; pp. 1-32.

48. Skoyles, E.; Skoyles, J. Waste Prevention on Site; BT Batsford Limited: London, UK, 1987.

49. Jain, M. Economic Aspects of Construction Waste Materials in terms of cost savings-A case of Indian construction Industry. Int. J. Sci. Res. Publ. 2012, 2, 1-7. [CrossRef]

50. Kofoworola, O.F.; Gheewala, S.H. Estimation of construction waste generation and management in Thailand. Waste Manag. 2009, 29, 731-738. [CrossRef] [PubMed]

51. Chau, K.W.; Chan, I.Y.S.; Lu, W.; Webster, C. (Eds.) In Proceedings of the 21st International Symposium on Advancement of Construction Management and Real Estate; Springer: Singapore, 2017; pp. 1-1558.

52. Wang, J.; Wu, H.; Tam, V.W.; Zuo, J. Considering life-cycle environmental impacts and society's willingness for optimizing construction and demolition waste management fee: An empirical study of China. J. Clean. Prod. 2019, 206, 1004-1014. [CrossRef]

53. Shen, L.Y.; Tam, V.W.Y.; Tam, C.M.; Drew, D. Mapping Approach for Examining Waste Management on Construction Sites. J. Constr. Eng. Manag. 2004, 130, 472-481. [CrossRef]

54. Poon, C.S. Reducing construction waste. Waste Manag. 2007, 27, 1715-1716. [CrossRef]

55. Tchobanoglous, G.; Theisen, H.; Vigil, S. Integrated Solid Waste Management: Engineering Principles and Management Issues; McGrawHill: New York, NY, USA, 1993; pp. 1-978.

56. El-Haggar, S. Chapter 8-Sustainability of Construction and Demolition Waste Management. In Sustainable Industrial Design and Waste Management Cradle-to-Cradle for Sustainable Development; Elsevier: London, UK, 2007; pp. 261-292. [CrossRef]

57. Saez, P.-V.; del Río Merino, M.; Porras Amores, C.; de San Antonio Gonzalez, A. European legislation, and implementation measures in the management of construction and demolition waste. Open Constr. Build. Technol. J. 2011, 5, 156-161. [CrossRef]

58. Gálvez-Martos, J.-L.; Styles, D.; Schoenberger, H.; Zeschmar-Lahl, B. Construction and demolition waste best management practice in Europe. Resour. Conserv. Recycl. 2018, 136, 166-178. [CrossRef]

59. Nagapan, S.; Rahman, I.A.; Asmi, A. Factors contributing to physical and non-physical waste generation in construction industry. Int. J. Adv. Appl. Sci. 2012, 1, 1-10. [CrossRef]

60. Serpell, A.; Alarcón, L.F. Construction process improvement methodology for construction projects. Int. J. Proj. Manag. 1998, 16, 215-221. [CrossRef]

61. Skoyles, E.R. Materials wastage-A misuse of resources. Batim. Int. Build. Res. Pract. 1976, 4, 232. [CrossRef]

62. Crocker, R. Unmaking waste. In Routledge Handbook of Sustainable Product Design; Routledge: Oxford, UK, 2017 ; pp. $250-265$.

63. Alarcon, L.F. Training field personnel to identify waste and improvement opportunities in construction. In Lean Construction; CRC Press: Boca Raton, FL, USA, 1997; pp. 402-413.

64. Gharfalkar, M.; Court, R.; Campbell, C.; Ali, Z.; Hillier, G. Analysis of waste hierarchy in the European waste directive 2008/98/EC. Waste Manag. 2015, 39, 305-313. [CrossRef]

65. The European Commission. Directive 2008/98/EC on Waste (Waste Framework Directive); Official Journal of the European Union, European Commission (EC)-Environment: Brussels, Belgium, 2016; pp. 1-28.

66. Sáez, P.V.; Osmani, M. A diagnosis of construction and demolition waste generation and recovery practice in the European Union. J. Clean. Prod. 2019, 241, 118400. [CrossRef]

67. Arm, M.; Wik, O.; Engelsen, C.J.; Erlandsson, M.; Hjelmar, O.; Wahlström, M. How Does the European Recovery Target for Construction \& Demolition Waste Affect Resource Management? Waste Biomass Valorization 2017, 8, 1491-1504. [CrossRef]

68. The European Commission. EU Construction \& Demolition Waste Management Protocol; The European Commission: Brussels, Belgium, 2016; pp. 1-52.

69. Osmani, M.; Villoria-Sáez, P. Chapter 19-Current and Emerging Construction Waste Management Status, Trends and Approaches. In Waste: A Handbook for Management; Academic Press: Cambridge, MA, USA, 2019; pp. 365-380. [CrossRef]

70. The European Commission. Directive (EU) 2018/851 of the European Parliament and of the Council; Official Journal of the European Union; The European Commission: Brussels, Belgium, 2018; pp. 1-32.

71. El-Haggar, S.; Samaha, A. Roadmap for Global Sustainability—Rise of the Green Communities; Interdisciplinary Series for Sustainable Development; Springer International Publishing: New York, NY, USA, 2019; pp. 1-215. [CrossRef]

72. Cornell University Law School. 40 CFR 98.348-Definitions. Available online: https://www.law.cornell.edu/cfr/text/40/98.348 (accessed on 22 January 2021).

73. Gao, M.-Z.A. Construction \& Demolition Waste Management: From Japan to Hong Kong. Griffins View Int. Comp. Law 2008, 1-29.

74. AECOM. People's Republic of China: Construction and Demolition Waste Management and Recycling; Asian Development Bank, PRC Ministry of Housing and Urban-Rural Development: Hong Kong, China, 2015; pp. 1-272.

75. Gupta, S.; Malik, R. The Impact of C \& D Waste on Indian Environment: A Critical Review. Civ. Eng. Res. J. 2018, 5, 1-7. [CrossRef] 
76. Pickin, J.; Wardle, C.; O’Farrell, K.; Nyunt, P.; Donovan, S. National Waste Report 2020; Blue Environment Pty Ltd.: Docklands, Australia, 2020; pp. 1-156.

77. Shooshtarian, S.; Maqsood, T.; Khalfan, M.; Wong, P.; Yang, R. Construction and Demolition Waste Management in Australia: Review of Differences in Jurisdictional Regulatory Frameworks. In Proceedings of the CIB World Building Congress 2019 'Constructing Smart Cities', Hong Kong, China, 17-21 June 2019; pp. 1-11.

78. The Australian Government. The 2018 National Waste Policy: Less Waste More Resources; The Australian Government: Canberra, Australia, 2018.

79. Ramsay \& Associates, P. Review of the Regulatory Framework for the Management of Construction and Demolition and Inert Waste in Australian Jurisdictions; Waste Authority of Western Australia: Perth, Australia, 2011.

80. Sustainable Resource Use. Australian Waste Definitions. Defining Waste Related Terms by Jurisdiction in Australia; R01-02-A11306; Department of Sustainability, Environment, Water, Population and Communities: Canberra, Australia, 2012; pp. 1-28.

81. Crawford, R.H.; Mathur, D.; Gerritsen, R. Barriers to improving the environmental performance of construction waste management in remote communities. Procedia Eng. 2017, 196, 830-837. [CrossRef]

82. NT EPA. Waste Management Strategy for the Northern Territory 2015-2022; Northern Territory Environment Protection Authority: Darwin, Australia, 2015; pp. 1-24.

83. Sustainability Victoria. Statewide Waste and Resource Recovery Infrastructure Plan; Victoria State Government: Melbourne, Australia, 2018; pp. 1-176.

84. Queensland Government. Queensland Waste Data System-Glossary. Available online: https://www.qld.gov.au/environment/ pollution/management/waste/recovery/data-reports/qwds-glossary (accessed on 12 January 2021).

85. EPA SA. Waste Definitions EPA 842/19; Environment Protection Authority (EPA) of South Australia: Adelaide, Australia, 2019; pp. 1-16.

86. Crocker, R.; Saint, C.; Chen, G.; Tong, Y. (Eds.) Unmaking Waste in Production and Consumption: Towards the Circular Economy, 1st ed.; Emerald Publishing Limited: Bingley, UK, 2018; pp. 1-353.

87. Garcés-Ayerbe, C.; Rivera-Torres, P.; Suárez-Perales, I.; Leyva-De La Hiz, D.I. Is it possible to change from a linear to a circular economy? An overview of opportunities and barriers for European small and medium-sized enterprise companies. Int. J. Environ. Res. Public Health 2019, 16, 851. [CrossRef]

88. Arroyo, P.; Gonzalez, V. Rethinking waste definition to account for environmental and social impacts. In Proceedings of the IGLC 2016-24th Annual Conference of the International Group for Lean Construction, Boston, MA, USA, 20-22 July 2016; pp. 20-22.

89. Muhwezi, L.; Chamuriho, L.; Lema, N. An investigation into materials wastes on building construction projects in KampalaUganda. Sch. J. Eng. Res. 2012, 1, 11-18.

90. Wu, H.; Zuo, J.; Yuan, H.; Zillante, G.; Wang, J. A review of performance assessment methods for construction and demolition waste management. Resour. Conserv. Recycl. 2019, 150, 104407. [CrossRef]

91. Themelis, N.J.; Mussche, C. Municipal solid waste management and waste-to-energy in the United States, China, and Japan. In Proceedings of the 2nd International Academic Symposium on Enhanced Landfill Mining, Houthalen-Helchteren, Belgium, 14-16 October 2013; pp. 14-16.

92. Laquatra, J.; Pierce, M. Waste Management at the Residential Construction Site. Cityscape 2014, 16, 313-318.

93. Arif, M.; Bendi, D.; Toma-Sabbagh, T.; Sutrisna, M. Construction waste management in India: An exploratory study. Constr. Innov. 2012, 12, 133-155. [CrossRef]

94. Bovea, M.D.; Powell, J.C. Developments in life cycle assessment applied to evaluate the environmental performance of construction and demolition wastes. Waste Manag. 2016, 50, 151-172. [CrossRef] [PubMed]

95. Panchasara, H.; Samrat, N.H.; Islam, N. Greenhouse Gas Emissions Trends and Mitigation Measures in Australian Agriculture Sector-A Review. Agriculture 2021, 11, 85. [CrossRef] 